\title{
Association of Serum Magnesium and Blood Pressure in Patients with Hypertensive Crises: A Retrospective Cohort Study
}

IfeanyiChukwu 0. Onor ( $\square$ ionor@xula.edu )

CardioRenal Research Group (CRRG), College of Pharmacy, Xavier University of Louisiana

Lashira M. Hill

CardioRenal Research Group (CRRG), College of Pharmacy, Xavier University of Louisiana

Modupe M. Famodimu

CardioRenal Research Group (CRRG), College of Pharmacy, Xavier University of Louisiana

Mallory R. Coleman

CardioRenal Research Group (CRRG), College of Pharmacy, Xavier University of Louisiana

Carolkim H. Huynh

CardioRenal Research Group (CRRG), College of Pharmacy, Xavier University of Louisiana

Robbie A. Beyl

Pennington Biomedical Research Center

\section{Casey J. Payne}

CardioRenal Research Group (CRRG), College of Pharmacy, Xavier University of Louisiana

Emily K. Johnston

CardioRenal Research Group (CRRG), College of Pharmacy, Xavier University of Louisiana John I. Okogbaa

CardioRenal Research Group (CRRG), College of Pharmacy, Xavier University of Louisiana Christopher J. Gillard

CardioRenal Research Group (CRRG), College of Pharmacy, Xavier University of Louisiana

Daniel F. Sarpong

Center for Minority Health and Health Disparities Research and Education, College of Pharmacy, Xavier University of Louisiana

Amne Borghol

CardioRenal Research Group (CRRG), College of Pharmacy, Xavier University of Louisiana

\section{Samuel C. Okpechi}

Department of Biochemistry and Molecular Biology, Louisiana State University Health Sciences Center

Ifeyinwa Norbert

CardioRenal Research Group (CRRG), College of Pharmacy, Xavier University of Louisiana

\section{Shane E. Sanne}

Department of Medicine, Louisiana State University Health Sciences Center School of Medicine 


\section{Shane G. Guillory}

Department of Medicine, Louisiana State University Health Sciences Center School of Medicine

\section{Research Article}

Keywords: Magnesium, Blood Pressure, Hypertensive Crises

Posted Date: March 3rd, 2021

DOI: https://doi.org/10.21203/rs.3.rs-257346/v1

License: (c) (1) This work is licensed under a Creative Commons Attribution 4.0 International License. Read Full License 
2 Association of Serum Magnesium and Blood Pressure in Patients with Hypertensive Crises: A

3 Retrospective Cohort Study

4

6 IfeanyiChukwu O. Onor, Pharm.D., BCPS, FNKF ${ }^{1,2,3}$

7 Lashira M. Hill, Pharm.D. ${ }^{1}$

8 Modupe M. Famodimu, Pharm.D., BCPS ${ }^{1}$

9 Mallory R. Coleman, Pharm.D. ${ }^{1}$

10 Carolkim H. Huynh, Pharm.D. ${ }^{1}$

11 Robbie A. Beyl, Ph.D. ${ }^{4}$

12 Casey J. Payne, Pharm.D. ${ }^{1}$

13 Emily K. Johnston, Pharm.D., BCCCP ${ }^{1}$

14 John I. Okogbaa, Pharm.D., BCPS ${ }^{1,2}$

15 Christopher J. Gillard, Pharm.D., BCPS ${ }^{1,2,3}$

16 Daniel F. Sarpong, Ph.D. ${ }^{1,5}$

17 Amne Borghol, Pharm.D., BCPS $1,2,3$

18 Samuel C. Okpechi, B.S. ${ }^{6}$

19 Ifeyinwa Norbert, M.D. ${ }^{1}$

20 Shane E. Sanne, D.O. ${ }^{2}$

21 Shane G. Guillory, M.D. ${ }^{2}$

22 CardioRenal Research Group (CRRG)

23

24 
$25{ }^{1}$ CardioRenal Research Group (CRRG), College of Pharmacy, Xavier University of Louisiana, 1 Drexel

26 Drive, New Orleans, LA 70125

$27 \quad{ }^{2}$ Department of Medicine, Louisiana State University Health Sciences Center School of Medicine, 1542

28 Tulane Avenue, New Orleans, LA 70112

$29{ }^{3}$ Department of Pharmacy, University Medical Center New Orleans, 2000 Canal Street, New Orleans, LA

$30 \quad 70112$

$31{ }^{4}$ Pennington Biomedical Research Center, 6400 Perkins Road, Baton Rouge, LA 70808

$32{ }^{5}$ Center for Minority Health and Health Disparities Research and Education, College of Pharmacy, Xavier

33 University of Louisiana, 1 Drexel Drive, New Orleans, LA 70125, USA

$34{ }^{6}$ Department of Biochemistry and Molecular Biology, Louisiana State University Health Sciences Center,

351901 Perdido Street, New Orleans, LA 70112

36

37 Corresponding Author: IfeanyiChukwu O. Onor, Pharm.D., BCPS, FNKF

38

39

40

41

42

43

44

45

46

47

48 
Abstract

51 Background: The role of magnesium in blood pressure has been studied among hypertensive patients,

52 however, no study has explored the role of magnesium in hypertensive crises. The primary objective of

53 this study is to evaluate the relationship between serum magnesium and blood pressure in patients with

54 hypertensive crises.

56 Methods: This study is a single-center, retrospective, chart review, cohort study of patients with

57 hypertensive crises. Patients were included in the study cohort if they were eighteen years of age or

58 older with an international classification disease ninth revision (ICD-9) code of 401.9 (hypertensive

59 crises: emergency or urgency) and a documented magnesium level on their electronic medical record.

60 The primary outcome of the study was to assess the correlation between serum magnesium on blood

61 pressure (systolic blood pressure and diastolic blood pressure) in patients with hypertensive crises. The

62 secondary outcomes were to assess the association between serum calcium, corrected calcium, and

63 serum potassium on blood pressure in patients with hypertensive crises and to determine the effects of

64 covariates in modulating the relationship between serum magnesium and blood pressure.

66 Results: Two hundred and ninety-three patients were included in the study. The primary outcome result

67 showed that serum magnesium was positively correlated with systolic blood pressure ( $r=0.143$,

$68 \mathrm{p}=0.014)$, but not diastolic blood pressure. Serum calcium was also found to be positively correlated

69 with systolic blood pressure, but not diastolic blood pressure. After adjusting for covariates in the

70 solution for fixed effects analysis, serum magnesium, serum calcium, corrected calcium, and use of

71 home proton pump inhibitors were correlated with systolic blood pressure at crises; while age, serum

72 calcium, and corrected calcium were significantly correlated with diastolic blood pressure at crises. 
74 Conclusion: This study found a significant positive association between magnesium and systolic blood

75 pressure, but not diastolic blood pressure among patients with hypertensive crises. This positive

76 association of serum magnesium with systolic blood pressure was maintained after adjusting for

77 covariates. This study findings suggests a potential role of magnesium in blood pressure among patients

78 with hypertensive crises. Future studies should evaluate the role of serum magnesium modifying

79 therapies in controlling blood pressure in patients with hypertensive crises.

80

81

82 Keywords: Magnesium, Blood Pressure, Hypertensive Crises

83

84

85

86

87

88

89

90

91

92

93

94

95

96 
98 Magnesium is the second most abundant intracellular cation after potassium and the fourth most

99 abundant cation in the body (1-3). In adult humans, total body magnesium store is approximately 24

100 grams with 99\% existing intracellularly [bone (53\%), muscle (27\%), and soft tissue (19\%)] and $1 \%$ existing

101 in the extracellular space (serum and erythrocytes) (1,2). Normal total serum concentration is in the

102 range of $1.7-2.6 \mathrm{mg} / \mathrm{dL}(0.7-1.1 \mathrm{mmol} / \mathrm{L})(1)$. This serum magnesium range represents approximately

$1030.3 \%$ of total body magnesium and may not accurately reflect the total magnesium status $(2,4)$. Ten

104 percent of serum magnesium is complexed to serum anions, thirty percent of serum magnesium is

105 albumin-bound, and sixty percent of serum magnesium exists in the ionized, free physiologically active

106 form (1). Serum magnesium homeostasis is regulated by the interplay between intestinal transport,

107 bone transport, and renal exchange (1). Magnesium is involved in a plethora of physiologic processes in

108 the body namely: intracellular signaling, serving as a cofactor for DNA \& protein synthesis, oxidative

109 phosphorylation, cardiac excitability, vasomotor tone, blood pressure regulation, neuromuscular

110 transmission, and bone formation (1-3).

112 Hypertension is a condition characterized by elevation in the systolic blood pressure (SBP) and/or

113 diastolic blood pressure (DBP) (5,6). Clinical practice guidelines define hypertension using different

114 cutpoints as either SBP $\geq 130 \mathrm{mmHg}$ and/or DBP $\geq 80 \mathrm{mmHg}$ (7) or SBP $\geq 140 \mathrm{mmHg}$ and/or DBP $\geq 90$

$115 \mathrm{mmHg}(8,9)$. The global prevalence of hypertension in adults is between $30 \%-45 \%$; with a global age-

116 adjusted prevalence of $24 \%$ and $20 \%$ in men and women, respectively (9). The prevalence of

117 hypertension among US adults depends on the clinical practice guideline cutpoints to categorize blood

118 pressure; with an overall prevalence of hypertension among US adults between $32 \%$ - $46 \%$ and age-sex

119 adjusted prevalence range of $31 \%-48 \%$ for men and $32 \%-43 \%$ in women $(7,8)$. Hypertension remains a

120 leading risk factor for cardiovascular diseases (hemorrhagic stroke, ischemic stroke, myocardial 
121 infarction, angina, heart failure, peripheral artery disease, and aortic aneurysm), end-stage renal

122 disease, death, and disability (5-10). Hypertensive crises is defined as SBP greater than $180 \mathrm{mmHg}$

123 and/or DBP greater than $120 \mathrm{mmHg}(7,8)$. Hypertensive crises can be further classified into:

124 hypertensive urgency (when there is no evidence of target organ damage) and hypertensive emergency

125 (when there is evidence of target organ damage) $(7,8)$. Although hypertensive urgency reflects a marked

126 elevation in blood pressure, it can be managed by increasing or optimizing the dose of oral

127 antihypertensive agents. Hypertensive emergency, however, is characterized with target organ damage

128 and is associated with a 1-year mortality rate of $>79 \%$; thus necessitating swift blood pressure reduction

129 with intravenous antihypertensive agents to prevent sustained deterioration of target organ damage

$130(7,8)$. The principal focus of our study is to examine the role of magnesium on SBP and DBP in

131 hypertensive crises anchored by background evidence from studies evaluating the role of magnesium in

132 hypertension.

134 Multiple clinical trials have shown, albeit inconsistently, that magnesium deficiency (serum and/or

135 tissue) occurs to some degree in hypertensive subjects; with low magnesium levels linked to a significant 136 undesirable effect on blood pressure (11-16). Although magnesium has been postulated to modulate

137 blood pressure regulation, the precise mechanism of altered magnesium metabolism in hypertensive

138 individuals remain unclear (11). The prevalent postulated mechanism of the effect of magnesium on

139 blood pressure is that magnesium acts as a natural calcium antagonist on most types of calcium

140 channels in vascular smooth muscles, thus reducing arterial blood pressure through lowering of

141 peripheral and cerebral vascular resistance (11). More specifically, the activity of magnesium as a

142 calcium antagonist produces endothelial dependent vasodilation and reduction of blood pressure

143 through increases of extracellular magnesium and reduction of calcium influx $(4,11,17,18)$. Magnesium

144 has also been shown to produce vasodilation by increasing prostaglandin E - a vasodilator and platelet 
145 inhibitor $(17,18)$. Magnesium is also an essential cofactor for delta-6-desaturase enzyme which converts

146 linoleic acid to gamma linolenic acid, a precursor to prostaglandin E $(17,18)$. Additionally, a strong

147 interaction has been found between magnesium and other electrolytes (potassium, calcium, and

148 sodium) in blood pressure reduction; with reduction of intracellular sodium and calcium, and increases

149 in intracellular magnesium and potassium shown to improve blood pressure $(17,18)$.

150

151 Several observational clinical studies and a meta-analysis have evaluated the relationship between

152 serum magnesium and blood pressure in patients with and without hypertension $(12,14,25,15,16,19-$

153 24); however, no published study to our knowledge has evaluated serum magnesium and blood

154 pressure relationship among patients with hypertensive crises. The available published studies

155 performed tests of association (correlation, odds ratio, risk ratios, and hazard ratios) between

156 magnesium and either blood pressure or hypertension $(12,14,25,15,16,19-24)$. Among the ten studies

157 that performed a test of association between serum magnesium and either blood pressure or

158 hypertension, six studies found a significant negative association $(14-16,20,21,24)$, three studies found

159 no significant relationship $(12,19,23)$, and one study found a significant positive correlation between

160 serum magnesium and blood pressure in women only (25). The meta-analysis by Han et al. found no

161 significant association between serum magnesium and blood pressure, although there was a trend

162 towards negative association between serum magnesium and blood pressure (Risk Ratio $(\mathrm{RR})=0.91$,

$16395 \% \mathrm{Cl}: 0.80-1.02)(22)$. Collectively, these studies have revealed conflicting evidence on the

164 relationship between serum magnesium levels and either blood pressure or hypertension; with some

165 studies showing negative association (14-16,20,21,24), and others showing either no association

$166(12,19,22,23,25)$ or a positive association (25). Similarly, the effect of magnesium supplementation on

167 blood pressure has been studied extensively. Nine out of the ten studies (clinical trials, Cochrane Review

168 and meta-analyses) reviewed showed mostly positive association/effect of magnesium supplementation 
169 in lowering SBP, DBP, or both $(22,26-33)$; and only one study found no significant effect of magnesium

170 supplementation on blood pressure (34). This prevailing positive effect of magnesium supplementation

171 in lowering blood pressure proved compelling and served as the foundational rationale for our study

172 evaluating whether serum magnesium is a factor that contributes to the dysregulated high blood

173 pressure seen in patients with hypertensive crises. We hypothesized that low serum magnesium will be

174 significantly associated with blood pressure (SBP and DBP) in patients with hypertensive crises.

176 The primary objective of this study is to evaluate the correlation between serum magnesium and blood

177 pressure (SBP and DBP) in hypertensive crises. Secondary objectives were to evaluate the association

178 between serum calcium, corrected calcium, and serum potassium on blood pressure in patients with

179 hypertensive crises, and to determine the effects of covariates [age, sex, race, body mass index (BMI),

180 history of diabetes mellitus, use of proton pump inhibitors at home, use of blood pressure medications

181 at home or hospital, use of oral magnesium at home, use of intravenous magnesium at hospital, serum

182 calcium at crises, corrected calcium at crises, and serum potassium at crises] in modulating the

183 relationship between serum magnesium and blood pressure.

184

185

186

187

188

189

190

191

192 


\section{Study Design and Methods:}

194 This study is a single-center, retrospective, chart review, cohort study conducted at the Interim

195 Louisiana State University Hospital (ILH) - New Orleans, Louisiana. The study cohort data was reviewed

196 from patients who were admitted to ILH with hypertensive crises during a 2-year period from July 2012

197 to July 2014. This study was approved by the Xavier University of Louisiana Institutional Review Board

198 (IRB) and ILH Research Review Committee (RRC).

200 Patients who were eighteen years of age or older with an international classification disease ninth

201 revision (ICD-9) code of 401.9 (hypertensive crises: emergency or urgency) and a documented

202 magnesium level on their electronic medical record (during the hypertensive crises hospital admission)

203 were included in the study cohort. Hypertensive crises was defined as systolic blood pressure (SBP)

204 greater than $180 \mathrm{mmHg}$ and/or diastolic blood pressure (DBP) greater than $120 \mathrm{mmHg}$. Patients

205 identified as having hypertensive crises based on ICD-9 codes were confirmed to have either systolic

206 blood pressure (SBP) greater than $180 \mathrm{mmHg}$ and/or diastolic blood pressure (DBP) greater than 120

$207 \mathrm{mmHg}$. Hypertensive crises was further categorized as either hypertensive urgency (absence of acute or

208 on-going target organ damage) or hypertensive emergency (presence of acute or on-going target-organ

209 damage). Target organ damage by system included neurologic (hypertensive encephalopathy,

210 intracranial hemorrhage, acute ischemic stroke), cardiac (acute myocardial infarction, acute left

211 ventricular failure, unstable angina, dissecting aortic aneurysm), and renal (acute kidney injury). All

212 diagnoses of target organ damage were confirmed with both the physician diagnosis documented on

213 the patients' problem list and clinical findings (laboratory results, imaging, signs, and symptoms) made

214 on the patients. Hypertensive encephalopathy diagnosis was verified based on physical exam findings of

215 headache and altered level of consciousness. Diagnosis of intracranial hemorrhage and acute ischemic

216 stroke was confirmed using a computed tomography (CT) scan or magnetic resonance imaging of the 
217 head with or without contrast, and was performed on patients with neurologic symptoms, which

218 includes change in mental status or focal neurologic signs indicative of cerebrovascular accident or

219 hemorrhage. Unstable angina diagnosis was made clinically and confirmed with documented new or

220 sudden chest pain, while myocardial infarction diagnosis was confirmed with elevated serum troponin

221 levels and electrocardiogram (EKG) findings. Acute left ventricular failure was diagnosed with

222 echocardiographic findings of a decreased ejection fraction less than $40 \%$ as well as physical exam

223 findings of elevated jugular venous pressure (distension), crackles, or edema. Diagnosis of dissecting

224 aortic aneurysm was confirmed from imaging studies revealing wide mediastinum on chest x-ray and/or

225 chest CT scan with or without contrast. Acute kidney injury was defined as a serum creatinine ( $\mathrm{SCr}$ )

226 greater than $2 \mathrm{mg} / \mathrm{dL}$, which is new onset in absence of prior renal disease and/or increase in SCr of 0.5

$227 \mathrm{mg} / \mathrm{dL}$ or greater.

228

229 Patients were excluded if they had conditions interfering with serum magnesium levels such as: chronic

230 kidney disease (CKD) stages 4 and 5, end-stage renal disease (ESRD), hepatic cirrhosis,

231 pheochromocytoma, chronic diarrhea, and hyperaldosteronism. Additionally, patients who received

232 inotropes or vasopressors (including epinephrine, norepinephrine, dopamine, phenylephrine,

233 vasopressin, dobutamine, or milrinone) during the hospital encounter were excluded from the study.

235 All patient data was obtained from ILH's electronic medical record. The following demographic data was

236 collected: age, sex, race, body mass index (BMI), and history of diabetes mellitus. Outcome variables

237 collected included serum magnesium $(\mathrm{mg} / \mathrm{dL})$, serum calcium $(\mathrm{mg} / \mathrm{dL})$, serum potassium $(\mathrm{mEq} / \mathrm{L}), \mathrm{SBP}$

$238(\mathrm{mmHg})$, and DBP ( $\mathrm{mmHg})$. All outcome variables were collected at a time closest to the first

239 documented hypertensive crises' blood pressure during the hospital encounter and is denoted as "at

240 crises". Additionally, maximum and minimum values of SBP and DBP were recorded within 24-hours of 
241 the first recorded hypertensive crises' blood pressure. Corrected calcium (mg/dL) was calculated using

242 the formula: corrected calcium = patient's measured serum calcium in $\mathrm{mg} / \mathrm{dL}+(0.8 *(4 \mathrm{gm} / \mathrm{dL}-$

243 patient's measured albumin in $\mathrm{gm} / \mathrm{dL}))$. The corrected calcium was only calculated for patients whose

244 serum albumin was less than $4 \mathrm{gm} / \mathrm{dL}$. Additional predictor variables collected include: home and

245 hospital use of blood pressure medications [inclusive of all blood pressure medication classes (for

246 example: calcium channel blockers) grouped in the electronic health record], at home use of proton

247 pump inhibitors, home use of oral magnesium, hospital use of intravenous magnesium, and albumin

248 levels (gm/dL).

\section{Outcomes}

251 The primary outcome of the study was to assess the correlation between serum magnesium on blood

252 pressure (SBP and DBP) in patients with hypertensive crises. The secondary outcomes of this study were

253 to evaluate the association between serum calcium, corrected calcium, and serum potassium on blood

254 pressure in patients with hypertensive crises, and to determine the effects of covariates (age, sex, race,

255 BMI, history of diabetes mellitus, use of proton pump inhibitors at home, use of blood pressure

256 medications at home or hospital, use of oral magnesium at home, use of intravenous magnesium at

257 hospital, serum calcium at crises, corrected calcium at crises, and serum potassium at crises) in

258 modulating the relationship between serum magnesium and blood pressure. An additional exploratory

259 outcome was to perform correlation analyses of serum magnesium, serum calcium, corrected calcium,

260 and serum potassium on the two independent variables: SBP and DBP measured at different time

261 points. 
266 We performed a power analysis based on findings of our primary outcome variables (serum magnesium,

267 SBP, and DBP) from prior studies. $(16,26,28)$ Based on these studies, we estimate that the $\mathrm{R}^{2}$ (coefficient

268 of determination) for the linear regression between serum magnesium and either SBP or DBP will range

269 between of $0.06-0.56$. Our power analysis revealed that the target sample size for this study will range

270 between $140-180$ subjects, to give us a power of 0.80 at a significance level of $5 \%$.

271

272 Descriptive statistical analysis was performed on demographic characteristics. Measures of central

273 tendency were obtained for continuous measures and frequency distribution for categorical measures.

274 Simple linear regression was performed to assess the correlation $(r)$ and coefficient of determination

$275\left(R^{2}\right)$ between serum magnesium, serum calcium, corrected calcium, and serum potassium on blood

276 pressure (SBP and DBP) in patients with hypertensive crises. A linear model analysis was performed to

277 assess effects of serum magnesium (and other electrolytes) on blood pressure (SBP and DBP) at the time

278 of hypertensive crises while adjusting for covariates. Statistical analyses were performed using SAS ${ }^{\circledR}$

279 version 9.4. An alpha value of less than 0.05 was considered statistically significant.

280

281

282

283

284

285

286

287

288 


\section{Results:}

290

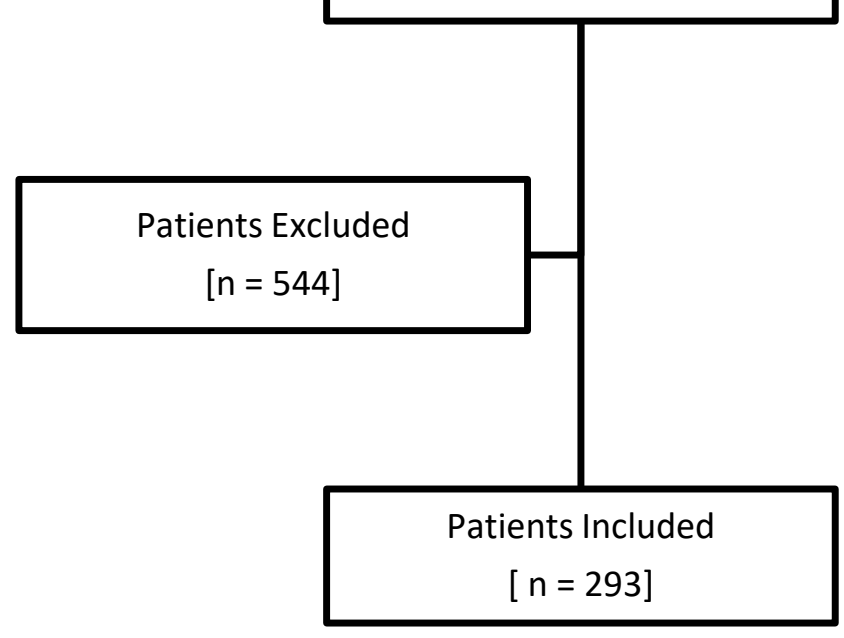

Patients Screened

$$
\text { [ } \mathrm{n}=837]
$$

292

293 Figure 1. Flow chart of inclusion to study cohort.

294

295

296

297

298

299

300

301

302

303

304 
Table 1. Baseline Characteristics ( $N=293$ )

\begin{tabular}{|c|c|}
\hline Demographic variables & \\
\hline Age [Mean \pm SD years; (range)] & $56.70 \pm 12.86(19-97)$ \\
\hline \multirow[t]{2}{*}{ Sex } & Male: 146 (49.83\%) \\
\hline & Female: 147 (50.17\%) \\
\hline \multirow[t]{4}{*}{ Race } & White: 62 (21.16\%) \\
\hline & Black/African-American: 213 (72.7\%) \\
\hline & Asian: $3(1.02 \%)$ \\
\hline & Other: 15 (5.12\%) \\
\hline \multirow[t]{2}{*}{ Hypertensive Crises Diagnosis } & Hypertensive Urgency: 220 (75.09\%) \\
\hline & Hypertensive Emergency: 73 (24.91\%) \\
\hline \multirow[t]{2}{*}{ History of Diabetes mellitus } & Diabetic: 102 (34.81\%) \\
\hline & Non-diabetic: 191 (65.19\%) \\
\hline Body Mass Index (BMI) [Mean \pm SD kg/m²; (range)] $(\mathrm{N}=290)$ & $30.59 \pm 9.33(16.70-69.10)$ \\
\hline Use of Home Proton Pump Inhibitors ( $N=259)$ & $53(20.46 \%)$ \\
\hline Use of Home Blood Pressure Medications $(\mathrm{N}=264)$ & $227(85.98 \%)$ \\
\hline Use of Hospital Blood Pressure Medications & $283(96.59 \%)$ \\
\hline Use of Home Magnesium (Oral) $(\mathrm{N}=292)$ & $31(10.62 \%)$ \\
\hline Use of Hospital Magnesium (Intravenous) ( $\mathrm{N}=292)$ & $95(32.53)$ \\
\hline Serum Magnesium at Crises (Mean \pm SD mg/dL; (range)] & $1.93 \pm 0.36(0.80-3.90)$ \\
\hline Serum Calcium at Crises (Mean \pm SD mg/dL; (range)] & $8.92 \pm 0.92(0.80-13.10)$ \\
\hline $\begin{array}{l}\text { Corrected Calcium at Crises (Mean } \pm \text { SD mg/dL; (range)] } \\
(\mathrm{N}=207)\end{array}$ & $9.33 \pm 0.90(1.12-13.34)$ \\
\hline
\end{tabular}




\begin{tabular}{|l|l|}
\hline Serum Potassium at Crises (Mean \pm SD mg/dL; (range)] & $3.92 \pm 0.64(1.40-6.30)$ \\
\hline Systolic Blood Pressure [Mean \pm SD mmHg; (range)] & $194.2 \pm 21.31(136-265)$ \\
\hline Diastolic Blood Pressure [Mean \pm SD mmHg; (range)] & $113.7 \pm 21.38(53-180)$ \\
\hline
\end{tabular}

308 Table 2. Association of serum magnesium (other electrolytes) and SBP at Crises or DBP at Crises

\begin{tabular}{|c|c|c|c|}
\hline \multicolumn{4}{|c|}{ Relationship between magnesium and SBP at Crises or DBP at Crises ( $\mathrm{N}=293$ ) } \\
\hline \multirow[b]{2}{*}{ Variables } & \multicolumn{3}{|c|}{ SBP at Crises } \\
\hline & $\mathbf{r}$ & $\mathbf{R}^{2}$ & P-value \\
\hline Serum Magnesium & 0.143 & 0.020 & 0.014 \\
\hline Serum Calcium & 0.187 & 0.035 & 0.001 \\
\hline Corrected Calcium ( $\mathrm{N}=\mathbf{2 0 7})$ & 0.049 & 0.002 & 0.482 \\
\hline \multirow[t]{2}{*}{ Serum Potassium } & -0.076 & 0.006 & 0.195 \\
\hline & \multicolumn{3}{|c|}{ DBP at Crises } \\
\hline Variables & $\mathbf{r}$ & $\mathbf{R}^{\mathbf{2}}$ & P-value \\
\hline Serum Magnesium & 0.033 & 0.001 & 0.570 \\
\hline Serum Calcium & 0.090 & 0.008 & 0.124 \\
\hline Corrected Calcium ( $\mathrm{N}=207$ ) & -0.011 & 0.000 & 0.873 \\
\hline Serum Potassium & -0.113 & 0.013 & 0.053 \\
\hline
\end{tabular}


314 Table 3. Association of serum magnesium and SBP at Crises or DBP at Crises using linear models

315 (adjusted for covariates)

\begin{tabular}{|c|c|c|}
\hline \multicolumn{3}{|c|}{ Relationship between serum magnesium and SBP at Crises or DBP at Crises ( $N=293$ ) } \\
\hline \multirow[b]{2}{*}{ Variables } & \multicolumn{2}{|l|}{ SBP at Crises } \\
\hline & $\beta \pm S E$ & P-value \\
\hline \multirow[t]{2}{*}{ Serum Magnesium } & $11.25 \pm 4.67$ & 0.017 \\
\hline & \multicolumn{2}{|l|}{ DBP at Crises } \\
\hline Variables & $\beta \pm S E$ & P-value \\
\hline Serum Magnesium & $2.56 \pm 4.93$ & 0.6031 \\
\hline \multicolumn{3}{|c|}{$\begin{array}{l}\text { Adjusted for covariates - Age, sex, race, history of diabetes, BMI, use of proton pump inhibitors at } \\
\text { home, use of blood pressure medications at home or hospital, use of oral magnesium at home, use of } \\
\text { intravenous magnesium at hospital, serum calcium at crises, corrected calcium at crises, and serum }\end{array}$} \\
\hline
\end{tabular}


327 Table 4. Best Predictor Variables on SBP at Crises using linear models (adjusted for covariates)

\begin{tabular}{|c|c|c|}
\hline & SBP at Crises & \\
\hline Predictor Variables & $\beta \pm S E$ & P-value \\
\hline Serum Magnesium & $11.25 \pm 4.67$ & 0.017 \\
\hline Serum Calcium & $9.50 \pm 3.37$ & 0.006 \\
\hline Corrected Calcium & $-7.82 \pm 3.54$ & 0.029 \\
\hline Use of Home Proton Pump Inhibitors & $9.13 \pm 3.85$ & 0.019 \\
\hline \multicolumn{3}{|c|}{$\begin{array}{l}\text { Covariates in the Mixed Model - Age, sex, race, history of diabetes, BMI, use of proton pump inhibitors } \\
\text { at home, use of blood pressure medications at home or hospital, use of oral magnesium at home, use } \\
\text { of intravenous magnesium at hospital, serum magnesium at crises, serum calcium at crises, corrected } \\
\text { calcium at crises, and serum potassium at crises. }\end{array}$} \\
\hline \multicolumn{3}{|c|}{ Alpha of $<0.05$ defined as significant for best predictor variables. } \\
\hline
\end{tabular}


339 Table 5. Best Predictor Variables on DBP at Crises using linear models (adjusted for covariates)

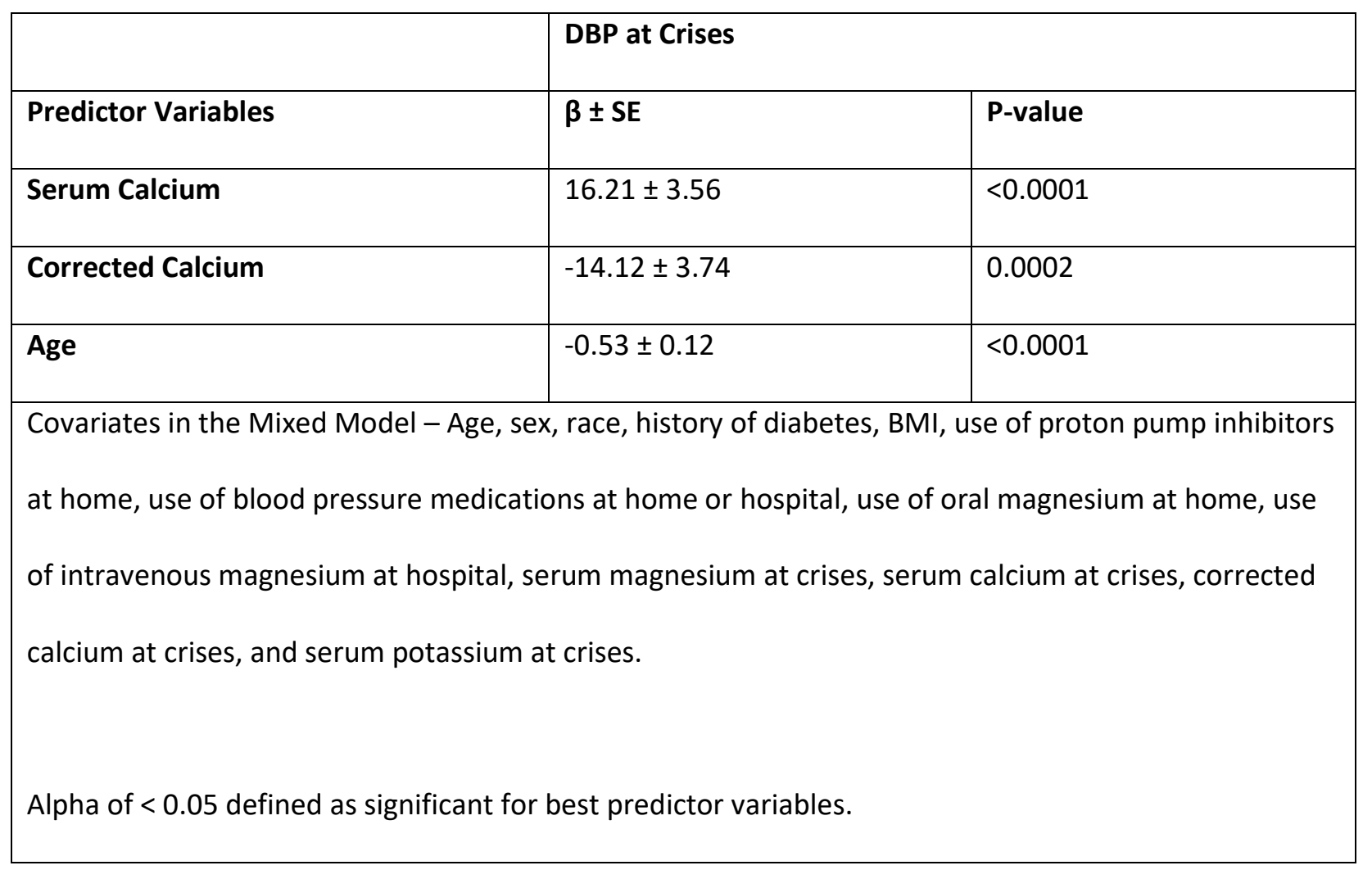


352 Table 6. Correlation of Serum Magnesium at Crises on SBP and DBP at different time points

\begin{tabular}{|l|l|l|l|}
\hline & \multicolumn{3}{l|}{ Serum Magnesium at Crises (N=293) } \\
\hline Variables & $\mathbf{r}$ & $\mathbf{R}^{2}$ & P-value \\
\hline SBP at Crises & 0.143 & 0.020 & 0.014 \\
\hline SBP Maximum (24-hr) & 0.104 & 0.011 & 0.074 \\
\hline SBP Minimum (24-hr) & -0.034 & 0.001 & 0.563 \\
\hline DBP at Crises & 0.033 & 0.001 & 0.570 \\
\hline DBP Maximum (24-hr) & 0.041 & 0.002 & 0.480 \\
\hline DBP Minimum (24-hr) & 0.021 & 0.000 & 0.726 \\
\hline
\end{tabular}

355 Table 7. Correlation of Serum Calcium at Crises on SBP and DBP at different time points

\begin{tabular}{|l|l|l|l|}
\hline & \multicolumn{3}{ll}{ Serum Calcium at Crises (N=293) } \\
\hline Variables & $\mathbf{r}$ & $\mathrm{R}^{2}$ & P-value \\
\hline SBP at Crises & 0.187 & 0.035 & 0.001 \\
\hline SBP Maximum (24-hr) & 0.134 & 0.018 & 0.022 \\
\hline SBP Minimum (24-hr) & 0.237 & 0.056 & $<0.0001$ \\
\hline DBP at Crises & 0.090 & 0.008 & 0.124 \\
\hline DBP Maximum (24-hr) & 0.121 & 0.015 & 0.038 \\
\hline DBP Minimum (24-hr) & 0.183 & 0.033 & 0.002 \\
\hline
\end{tabular}


360 Table 8. Effect of Corrected Calcium at Crises on SBP and DBP at different time points

\begin{tabular}{|l|l|l|l|}
\hline & \multicolumn{3}{ll}{ Corrected Calcium at Crises (N=207) } \\
\hline Variables & $\mathbf{r}$ & $\mathbf{R}^{2}$ & P-value \\
\hline SBP at Crises & 0.049 & 0.002 & 0.482 \\
\hline SBP Maximum (24-hr) & -0.028 & 0.001 & 0.690 \\
\hline SBP Minimum (24-hr) & 0.256 & 0.066 & 0.0002 \\
\hline DBP at Crises & & & \\
\hline DBP Maximum (24-hr) & -0.011 & 0.000 & 0.873 \\
\hline DBP Minimum (24-hr) & -0.000 & 0.000 & 0.996 \\
\hline & 0.177 & 0.031 & 0.011 \\
\hline
\end{tabular}

363 Table 9. Effect of Serum Potassium at Crises on SBP and DBP at different time points

\begin{tabular}{|l|l|l|l|}
\hline & \multicolumn{3}{ll}{ Serum Potassium at Crises } \\
\hline Variables & $\mathbf{r}$ & $\mathbf{R}^{2}$ & P-value \\
\hline SBP at Crises & -0.076 & 0.006 & 0.195 \\
\hline SBP Maximum (24-hr) & -0.074 & 0.005 & 0.209 \\
\hline SBP Minimum (24-hr) & -0.130 & 0.017 & 0.026 \\
\hline DBP at Crises & & & \\
\hline DBP Maximum (24-hr) & -0.113 & 0.013 & 0.053 \\
\hline DBP Minimum (24-hr) & -0.065 & 0.004 & 0.265 \\
\hline & -0.175 & 0.031 & 0.003 \\
\hline
\end{tabular}


Eight-hundred and thirty-seven patients who had a serum magnesium level and an ICD-9 code of 401.9

369 or a diagnosis of hypertensive crises, hypertensive urgency, and hypertensive emergency were identified

370 from ILH's electronic medical record (Figure 1). 544 patients were excluded after applying the study

371 exclusion criteria and 293 patients were included in the statistical analysis (Figure 1). Baseline

372 demographics are presented in table 1 . The majority of patients were African Americans (72.7\%) and the

373 mean age of patients in the study was 56.7 years. Hypertensive urgency $(75.1 \%)$ was greater in

374 prevalence than hypertensive emergency (24.9\%) among all hypertensive crises diagnosis. Nearly $35 \%$ of

375 patients had diabetes mellitus and the average BMI of the study population was $30.6 \mathrm{~kg} / \mathrm{m}^{2}$.

377 The primary outcome result is displayed on table 2 and showed that serum magnesium was positively

378 correlated $(r=0.143, p$-value $=0.014)$ with SBP at crises, but not DBP at crises. The coefficient of

379 determination $\left(\mathrm{R}^{2}\right)$ reveals that $2 \%$ of the variability in SBP at crises can be attributed to serum

380 magnesium. Beside serum magnesium, serum calcium was the only additional electrolyte significantly

381 correlated with SBP at crises. Serum calcium was positively correlated with SBP at crises, with $3.5 \%$ of

382 the variability in SBP at crises attributable to serum calcium. When evaluating DBP at crises, no

383 electrolyte was significantly correlated with DBP at crises; however, serum potassium showed a slight

384 trend towards negative correlation with DBP at crises.

386 Table 3 assessed the relationship with serum magnesium and both SBP and DBP at crises when adjusting

387 for covariates. The results showed that as serum magnesium increases by $1 \mathrm{mg} / \mathrm{dL}$, SBP at crises

388 increases $11.25 \mathrm{mmHg}$ after adjusting for covariates in the model ( $p$-value $=0.017$ ). Although a

389 significant association was found with serum magnesium and SBP at crises after adjusting for covariates,

390 no significant association was found with serum magnesium and DBP at crises after adjusting for

391 covariates in the model. 
392 Variables that significantly predicted SBP at time of hypertensive crises was assessed using a linear

393 model (adjusted for covariates) and the results are displayed on table 4. When adjusting for covariates,

394 serum magnesium, serum calcium, corrected calcium, and the use of proton pump inhibitors

395 independently emerged as the best variables that predicted SBP at crises, with all showing a positive

396 relationship with SBP at crises except for corrected calcium level showing a negative relationship with

397 SBP at crises. Similarly, table 5 displays the variables that best predicted DBP at time of hypertensive

398 crises using a linear model (adjusted for covariates). In the model, after adjusting for covariates, serum

399 calcium, corrected calcium, and age independently emerged as best variables that significantly predicted

400 DBP at crises. Serum calcium positively predicted DBP at crises in the model, while corrected calcium

401 and age negatively predicted DBP at crises in the model.

402

403 Tables 6 through 9 display a result of the correlation matrix analyses of serum magnesium, serum

404 calcium, corrected calcium, and serum potassium on the two independent variables: SBP and DBP

405 measured at different time points. Table 6 showed that serum magnesium was significantly correlated

406 only with SBP at time of crises and the maximum SBP measured within 24-hours of the first hypertensive

407 crises diagnosis. Results displayed on table 7 showed that serum calcium was significantly correlated

408 with SBP and DBP measured at different time points, with the exception of DBP measured at time of

409 crises not showing significant correlation with serum calcium. Corrected calcium results displayed on

410 table 8 revealed that corrected calcium was only significantly correlated with minimum SBP and

411 minimum DBP measured within 24-hours of the first hypertensive crises diagnosis. Lastly, serum

412 potassium was only significantly correlated (negative correlation) with minimum SBP and minimum DBP

413 measured within 24-hours of the first hypertensive crises diagnosis.

\section{Discussion}


416 This study contributes much new knowledge on the role of magnesium in patients with hypertensive

417 crises - a population where the role of magnesium has been sparsely evaluated. The primary outcome

418 of our study evaluated the relationship between magnesium and blood pressure (SBP and DBP) in

419 patients with hypertensive crises.

420

421 Using correlation analysis (table 2) and linear regression analysis (table 3), our study found a significant

422 positive correlation between serum magnesium and SBP at crises, but no significant relationship was

423 found between serum magnesium and DBP at crises. This finding of positive correlation between serum

424 magnesium and SBP in our study conflicts with majority of studies that assessed serum magnesium and

425 SBP which have predominantly shown significant negative correlation $(12,14-16,21,24,25)$. Among the

426 seven studies that evaluated the linear relationship (correlation coefficient) between magnesium and

427 either SBP or DBP $(12,14-16,21,24,25)$, majority of these studies ( $N=5$ out of $7,71.4 \%$ ) showed

428 negative relationship between serum magnesium and SBP $(14-16,21,24)$. One of the studies showed no

429 significant relationship between serum magnesium and SBP (12), while one study by Rinner et al.

430 approximated our study finding and revealed a positive relationship between serum magnesium and

431 SBP in women, but not in men (25). With respect to the relationship between serum magnesium and

432 DBP, majority of the studies ( $N=4$ out of $7,57 \%$ ) have shown non-significant relationship which is

433 consistent with our study findings $(12,14,24,25)$. However, three studies found negative correlation

434 between serum magnesium and DBP which contradicts our study results $(15,16,21)$. Our study finding

435 therefore is consistent with most of the available literature showing no strong relationship between

436 serum magnesium and DBP; however our study finding conflicts with the predominant negative linear

437 relationship observed between serum magnesium and SBP in studies. Altogether, our study's detection

438 of a significant positive association between serum magnesium and SBP in patients with hypertensive

439 crises suggests that serum magnesium may play an important role in the dysregulated blood pressure 
seen in patients with hypertensive crises. It is plausible to consider that our study may have had

441 disparate results from the literature due to potential sources of error from selection bias and

442 confounding variables.

444 Among the additional electrolytes (calcium, corrected calcium, and potassium) that we assessed for a 445 relationship with blood pressure, we found that serum calcium showed significant positive correlation to 446 SBP at crises, but not DBP at crises. After adjusting for covariates (tables 4 and 5), we found positive 447 relationship between serum calcium and both SBP and DBP at crises. Similar to our study finding, the 448 positive association of serum calcium to both SBP and DBP has been reported in several studies that 449 evaluated the linear relationship between serum calcium and blood pressure (16,35-39). It is important 450 to reinforce that our study found a relationship between serum calcium and both SBP and DBP at crises 451 after adjusting for covariates; however the correlation analysis without adjustment for covariates 452 showed significant positive correlation between serum calcium for SBP at crises, but not DBP at crises.

453 Corrected calcium was not significantly correlated to either SBP or DBP at crises. In the exploratory 454 results, we found that corrected calcium was positively associated with both minimum SBP and DBP 455 within 24-hour of hypertensive crises. The data with corrected calcium should be interpreted cautiously 456 given that we did not include 86 missing data among patients who did not have serum albumin less than $4574 \mathrm{gm} / \mathrm{dL}$. Potassium was also not significantly correlated to either SBP or DBP at crises, although there 458 was a trend towards a negative correlation between potassium and DBP at crises. This finding is 459 inconsistent with prior studies which have predominantly shown a negative correlation between serum 460 potassium and both SBP and DBP $(25,40-42)$. In the exploratory results (tables $6-9)$, we found that 461 serum potassium was negatively associated with both minimum SBP and DBP within 24-hour of 462 hypertensive crises. Calcium and potassium were measured because of strong linkages of these 463 electrolytes with blood pressure, especially in concert with magnesium $(7,13,15-18,25)$. 
464 The strengths of our study include our use of statistical tests that explored association between

465 variables, the pilot nature of our study, and the attainment of our study's desired sample size. We

466 performed regression analysis to examine the association between magnesium (and other electrolytes)

467 and blood pressure in hypertensive crises. Findings from the regression analysis provide us useful

468 information on the relationship between electrolytes and variables. This study is also a pilot/exploratory

469 study and is thus a hypothesis generating study and can provide population estimates to help determine

470 the appropriate sample size to study the effect of magnesium on hypertensive crises in future studies.

471 Lastly, our study reached and exceeded our desired sample size for the study which decreased the

472 probability of type II errors and improved the probability to detect significant differences that may exist

473 in the true population of patients from which our sample population was obtained.

475 Our study has several limitations which impact the internal and external validity of our study. First, this

476 study is a single-center study and as such limits the generalizability of our study to patients across

477 institutions. The findings from this single-center study should be extrapolated cautiously to individual

478 patients and patient populations with hypertensive crises. This study was a retrospective study which

479 introduces variability on the time when variables were available; since variables available from the

480 electronic medical record were not collected uniformly at specific times as would be the case in a

481 prospective study. Our study was also a non-interventional/non-experimental study which impacts the

482 internal validity and excludes our study from the ability to assess causation. Our study was not a

483 randomized study and confounding variables may have effect on our study results. Lastly, our study may

484 be susceptible to selection bias as a source of error due to the study inclusion/exclusion criteria and the

485 unique demographic distribution of the study patients at our hospital compared to our study's broad

486 target population of patients with hypertensive crises. Another important study limitation is that 
magnesium is predominantly an intracellular cation, thus, the serum magnesium obtained from the

488 electronic hospital record may not be a good reflection of patients' magnesium stores. $(1,2)$

\section{Conclusion}

491 This study found a significant positive association between magnesium and systolic blood pressure, but

492 not diastolic blood pressure among patients with hypertensive crises. This positive association of serum

493 magnesium with systolic blood pressure was maintained after adjusting for covariates. This study

494 findings suggests a potential role of magnesium in blood pressure among patients with hypertensive

495 crises. Large sample experimental studies are needed to evaluate the role of serum magnesium

496 modifying therapies in controlling blood pressure in patients with hypertensive crises. Future studies

497 should also evaluate the role of serum calcium modifying therapies in blood pressure control in patients

498 with hypertensive crises.

500 List of Abbreviations:

501 SBP, Systolic blood pressure

502 DBP, Diastolic blood pressure

503 ILH, Interim Louisiana State University Hospital

$504 \quad$ IRB, Institutional Review Board (IRB)

505 RRC, Research Review Committee

506 ICD-9, International classification disease ninth revision

507 CT, Computed Tomography

508 EKG, Electrocardiogram

$509 \mathrm{SCr}$, Serum creatinine

510 CKD, Chronic kidney disease 
511 ESRD, End-stage renal disease

512 BMI, Body Mass Index

513 r, Correlation

$514 \mathrm{R}^{2}$, Coefficient of determination

515

516 Acknowledgement

517 We thank the Interim Louisiana State University Hospital for allowing us to conduct this retrospective 518 study on their patient population.

$520 \quad$ Funding

521 This study was supported in part by several grants: RCMI - NIH/NIMHD5G12MD007595 and NIMHD

522 2U54MD007595-11 from the National Institute of Health (NIH), National Institute on Minority Health

523 and Health Disparities (NIMHD), and Research Centers in Minority Institutions Program (RCMI); Center

524 for Minority Health and Health Disparities Research and Education - 5 S21 MD 000100-12 from the

525 National Institute on Minority Health and Health Disparities (NIMHD); LaCATS - 1 U54 GM104940 and

526 2U54GM104940-02 from the National Institute of General Medical Sciences of the National Institutes of

527 Health, which funds the Louisiana Clinical and Translational Science Center (LaCATS); Xavier Center of

528 Excellence - HRSA D34HP00006 from the Health Resources and Service Administration of the

529 Department of Health and Human Services (DHHS); and Title III - Center for Undergraduate Research

530 (CUR) via U.S. Department of Education - Title III, Part B Program.

\section{Authors' contributions}

533 Research idea and study design: IOO, JIO, CJG, DFS; data acquisition: LMH, MMF, MRC, CHH, CJP, EKJ;

534 data analysis/interpretation: IOO, LMH, MMF, MRC, CHH, CJP, EKJ RAB, DFS, JIO, CJG, AB, SCO, IN, SES, 
535 SGG; statistical analysis: RAB, IOO, DFS; supervision or mentorship: IOO, JIO, CJG, DFS, AB, SES, SGG.

536 Each author contributed important intellectual content during manuscript drafting or revision, accepts

537 personal accountability for the author's own contributions, and agrees to ensure that questions

538 pertaining to the accuracy or integrity of any portion of the work are appropriately investigated and

539 resolved. The author(s) read and approved the final manuscript.

540

541 Ethics approval and consent to participate

542 This study was approved by the Xavier University of Louisiana Institutional Review Board (IRB) and ILH

543 Research Review Committee (RRC). All methods were carried out in accordance with relevant guidelines

544 and regulations. This study was a retrospective, chart-review, non-interventional study and was granted

545 a waiver of informed consent by the Xavier University of Louisiana Institutional Review Board (IRB) and

546 ILH Research Review Committee (RRC).

547

548 Consent for publication

$549 \quad$ Not applicable.

550

551 Competing interests

552 The authors have no financial disclosures

553

554

555

556

557

558 


\section{References}

560 1. Blaine J, Chonchol M, Levi M. Renal control of calcium, phosphate, and magnesium homeostasis.

$561 \quad$ Clin J Am Soc Nephrol. 2015;10(7):1257-72.

562 2. Fawcett WJ, Haxby EJ, Male DA. Magnesium: Physiology and pharmacology. Br J Anaesth

563 [Internet]. 1999;83(2):302-20. Available from: http://dx.doi.org/10.1093/bja/83.2.302

564 3. Champagne CM. Magnesium in hypertension, cardiovascular disease, metabolic syndrome, and

565 other conditions: A review. Nutr Clin Pract. 2008;23(2):142-51.

566 4. Kupetsky-Rincon EA, Uitto J. Magnesium: Novel applications in cardiovascular disease - A review 567 of the literature. Ann Nutr Metab. 2012;61(2):102-10.

568 5. Solomon CG, Taler SJ. Initial treatment of hypertension. N Engl J Med. 2018;378(7):636-44.

569 6. Oparil S, Acelajado MC, Bakris GL, Berlowitz DR, Cífková R, Dominiczak AF, et al. Hypertension. $570 \quad$ Nat Rev Dis Prim. 2018;4.

571 7. Whelton PK, Carey RM, Aronow WS, Casey DE, Collins KJ, Dennison Himmelfarb C, et al. 2017 572 ACC/AHA/AAPA/ABC/ACPM/AGS/APhA/ASH/ASPC/NMA/PCNA Guideline for the Prevention, 573 Detection, Evaluation, and Management of High Blood Pressure in Adults: A Report of the 574 American College of Cardiology/American Heart Association Task Force on Clinical Pr. J Am Coll $575 \quad$ Cardiol. 2018;71(19):e127-248.

576 8. National High Blood Pressure Education Program. The Seventh Report of the Joint National 577 Committee on Prevention, Detection, Evaluation, and Treatment of High Blood Pressure.

578 [Internet]. The Seventh Report of the Joint National Committee on Prevention, Detection, 579 Evaluation, and Treatment of High Blood Pressure. Bethesda (MD): National Heart, Lung, and 580 Blood Institute (US); 2004 [cited 2020 Mar 19]. Available from:

581 https://www.ncbi.nlm.nih.gov/books/NBK9630/

582 9. Williams B, Mancia G, Spiering W, Agabiti Rosei E, Azizi M, Burnier M, et al. 2018 ESC/ESH 
Guidelines for the management of arterial hypertension: The Task Force for the management of arterial hypertension of the European Society of Cardiology (ESC) and the European Society of Hypertension (ESH). Eur Heart J [Internet]. 2018 Aug 25;39(33):3021-104. Available from: https://doi.org/10.1093/eurheartj/ehy339

10. Mills KT, Stefanescu A, He J. The global epidemiology of hypertension. Nat Rev Nephrol [Internet]. 2020;1975. Available from: http://dx.doi.org/10.1038/s41581-019-0244-2

11. Geiger H, Wanner C. Magnesium in disease. CKJ Clin Kidney J. 2012;5(SUPPL. 1).

12. Resnick LM, Gupta RK, Laragh JH. Intracellular free magnesium in erythrocytes of essential hypertension: Relation to blood pressure and serum divalent cations. Proc Natl Acad Sci U S A. 1984;81(20 I):6511-5.

13. Resnick LM, Bardicef $\mathrm{O}$, Altura BT, Alderman $\mathrm{MH}$, Altura BM. Serum ionized magnesium: relation to blood pressure and racial factors. Am J Hypertens. 1997;10(12 Pt 1):1420-4.

14. Ma J, Folsom AR, Melnick SL, Eckfeldt JH, Sharrett AR, Nabulsi AA, et al. Associations of serum and dietary magnesium with cardiovascular disease, hypertension, diabetes, insulin, and carotid

15. Touyz RM, Milne FJ, Seftel HC, Reinach SG. Magnesium, calcium, sodium and potassium status in normotensive and hypertensive Johannesburg residents. South African Med J. 1987;72(6):37781.

16. Abbasi I ur R, Salim-ul-Haque, Kausar MW, Karira KA, Zubari NA. Correlation of divalent Cat ions $(\mathrm{Ca++}, \mathrm{Mg++})$ and Serum Renin in pateints of essential hypertension. J Pak Med Assoc. $2012 ; 62(2): 134-8$.

604 17. Houston MC, Harper KJ. Potassium, magnesium, and calcium: their role in both the cause and 605 treatment of hypertension. Vol. 10, Journal of clinical hypertension (Greenwich, Conn.). J Clin Hypertens (Greenwich); 2008. p. 3-11. 
607 18. Houston M. The role of magnesium in hypertension and cardiovascular disease. J Clin Hypertens.

$608 \quad 2011 ; 13(11): 843-7$.

609 19. Khan AM, Sullivan L, McCabe E, Levy D, Vasan RS, Wang TJ. Lack of association between serum magnesium and the risks of hypertension and cardiovascular disease. Am Heart J [Internet]. 2010;160(4):715-20. Available from: http://dx.doi.org/10.1016/j.ahj.2010.06.036

20. Peacock JM, Folsom AR, Arnett DK, Eckfeldt JH, Szklo M. Relationship of serum and dietary magnesium to incident hypertension: The Atherosclerosis Risk in Communities (ARIC) Study. Ann Epidemiol. 1999;9(3):159-65.

615 21. Guerrero-Romero F, Rodríguez-Morán M, Hernández-Ronquillo G, Gómez-Díaz R, Pizano-Zarate ML, Wacher NH, et al. Low Serum Magnesium Levels and Its Association with High Blood Pressure in Children. J Pediatr. 2016;168:93-98.e1.

618 22. Han H, Fang X, Wei X, Liu Y, Jin Z, Chen Q, et al. Dose-response relationship between dietary magnesium intake, serum magnesium concentration and risk of hypertension: A systematic review and meta-analysis of prospective cohort studies. Nutr J. 2017;16(1):1-12.

621 23. Joosten MM, Gansevoort RT, Mukamal KJ, Kootstra-Ros JE, Feskens EJM, Geleijnse JM, et al. Urinary magnesium excretion and risk of hypertension: the prevention of renal and vascular endstage disease study. Hypertension. 2013;61(6):1161-7.

624 24. Petersen B, Schroll M, Christiansen C, Transbø| I. Serum and Erythrocyte Magnesium in Normal 625 Elderly Danish People: Relationship to Blood Pressure and Serum Lipids. Acta Med Scand. 1977;201(1-6):31-4.

627 25. Rinner MD, Spliet-van Laar L, Kromhout D. Serum sodium, potassium, calcium and magnesium 628 and blood pressure in a Dutch population. J Hypertens [Internet]. 1989 [cited 2020 Apr 11];7(12):977-81. Available from: https://pubmed.ncbi.nlm.nih.gov/2628498/

630 26. Guerrero-Romero F, Rodríguez-Morán M. The effect of lowering blood pressure by magnesium 
supplementation in diabetic hypertensive adults with low serum magnesium levels: A randomized, double-blind, placebo-controlled clinical trial. J Hum Hypertens. 2009;23(4):245-51.

633 27. Sanjuliani AF, De Abreu Fagundes VG, Francischetti EA. Effects of magnesium on blood pressure 634 and intracellular ion levels of Brazilian hypertensive patients. Int J Cardiol. 1996;56(2):177-83.

635 28. Kawano Y, Matsuoka H, Takishita S, Omae T. Effects of magnesium supplementation in hypertensive patients: Assessment by office, home, and ambulatory blood pressures. Hypertension. 1998;32(2):260-5.

29. Kass L, Weekes J, Carpenter L. Effect of magnesium supplementation on blood pressure: A metaanalysis. Eur J Clin Nutr. 2012;66(4):411-8.

30. Zhang X, Li Y, Del Gobbo LC, Rosanoff A, Wang J, Zhang W, et al. Effects of Magnesium Supplementation on Blood Pressure: A Meta-Analysis of Randomized Double-Blind PlaceboControlled Trials. Hypertension. 2016;68(2):324-33.

643 31. Jee SHA, Miller ER, Guallar E, Singh VK, Appel LJ, Klag MJ. The effect of magnesium supplementation on blood pressure: A meta-analysis of randomized clinical trials. Am J

32. Rosanoff A, Plesset MR. Oral magnesium supplements decrease high blood pressure (SBP > $155 \mathrm{mmHg}$ ) in hypertensive subjects on anti-hypertensive medications: A targeted meta-analysis. Magnes Res. 2013;26(3):93-9.

649 33. Dickinson HO, Nicolson D, Campbell F, Beyer FR, Mason J. Potassium supplementation for the management of primary hypertension in adults. Cochrane Database Syst Rev. 2006;(1).

651 34. Rogiers P, Vermeier W, Kesteloot H, Stroobandt R. Effect of the infusion of magnesium sulfate during atrial pacing on ECG intervals, serum electrolytes, and blood pressure. Am Heart J. 1989;117(6):1278-83.

65435 Jorde R, Sundsfjord J, Fitzgerald P, Bønaa KH. Serum calcium and cardiovascular risk factors and 
diseases: The Tromso Study. Hypertension. 1999;34(3):484-90.

656 36. Kesteloot $\mathrm{H}$, Joossens J V. Relationship of serum sodium, potassium, calcium, and phosphorus with blood pressure. Belgian Interuniversity Research on Nutrition and Health. Hypertension. 1988;12(6):589-93.

659 37. Lind L, Jakobsson S, Lithell H, Wengle B, Ljunghall S. Relation of serum calcium concentration to metabolic risk factors for cardiovascular disease. Br Med J. 1988;297(6654):960-3.

38. Schutte R, Huisman HW, Schutte AE, Malan NT, Van Rooyen JM, Fourie CMT, et al. Serum calcium revisited: Associations with 24-h ambulatory blood pressure and cardiovascular reactivity in Africans. Hypertens Res. 2010;33(7):688-94.

664 39. Staessen J, Sartor F, Roels H, Bulpitt CJ, Claeys F, Ducoffre G, et al. The association between blood pressure, calcium and other divalent cations: A population study. J Hum Hypertens.

40. Goto A, Yamada K, Nagoshi H, Ishiyama A, Minami M, Uehara Y, et al. Relation of 24-h ambulatory blood pressure with plasma potassium in essential hypertension. Am J Hypertens. 1997;10(3):337-40.

41. Pikilidou MI, Lasaridis AN, Sarafidis PA, Tziolas IM, Zebekakis PE, Dombros N V., et al. Blood pressure and serum potassium levels in hypertensive patients receiving or not receiving antihypertensive treatment. Clin Exp Hypertens. 2007;29(8):563-73.

673 42. Bulpitt CJ, Shipley MJ, Semmence A. Blood pressure and plasma sodium and potassium. Clin Sci. 1981;61(Suppl.7):85-7. 
Figures

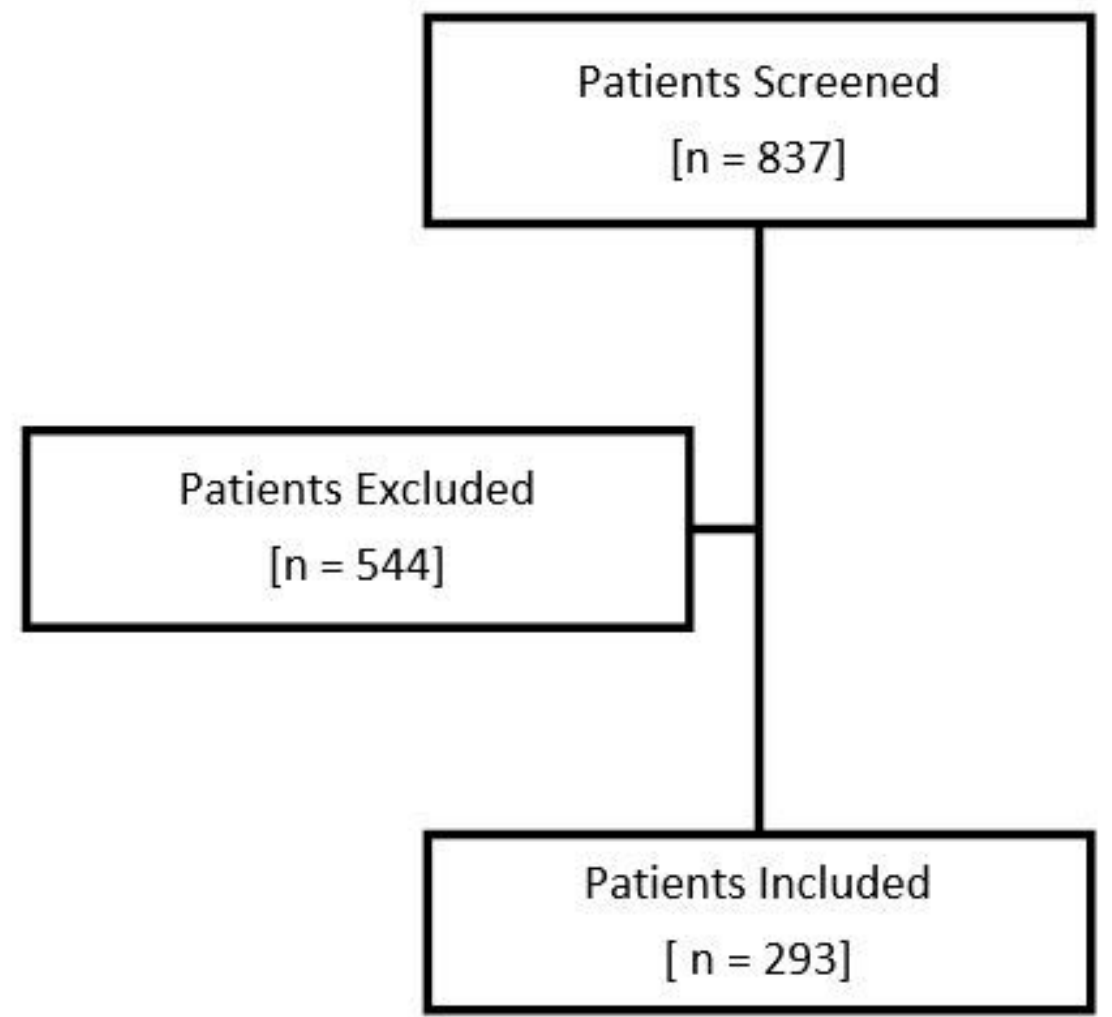

Figure 1

Flow chart of inclusion to study cohort. 